\title{
Genetic diversity of HLA system in four populations from Baja California, Mexico: Mexicali, La Paz, Tijuana and rural Baja California
}

\author{
Araceli Escobedo-Ruíz ${ }^{\mathrm{a}, 1}$, Rodrigo Barquera ${ }^{\mathrm{b}, \mathrm{c}, *, 1}$, Antonio González-Martín ${ }^{\mathrm{d}, 1}$, \\ Juan Manuel Argüelles-San Millán ${ }^{\mathrm{e}, 1}$, María Guadalupe Uribe-Duarte ${ }^{\mathrm{f}, 1}$, \\ Diana Iraíz Hernández-Zaragozac,g,1, Stephen Clayton ${ }^{\mathrm{b}, 1}$, Esteban Arrieta-Bolaños ${ }^{\mathrm{h}, 1}$, \\ María de Jesús Ruíz-Corral ${ }^{\mathrm{f}}$, Isis Goné-Vázquez ${ }^{\mathrm{a}}$, Francia Paulina Arellano-Prado,
} Julio César Martínez-Álvarez ${ }^{j}$, Víctor Eduardo García-Arias ${ }^{i}$, Marla Estefanía Rodríguez-López Alicia Bravo-Acevedo ${ }^{\mathrm{k}}$, María Guadalupe de Jesús Sánchez-Fernández ${ }^{1}$, Jesús Abraham Aguilar-Campos ${ }^{\mathrm{f}}$, Benjamín Gómez-Navarro ${ }^{\mathrm{m}}$, Mario J. Sandoval-Sandoval ${ }^{\mathrm{n}}$, Ricardo Serrano-Osuna ${ }^{\mathrm{f}}$, Edmond J. Yunis ${ }^{\mathrm{o}}$, Joaquín Zúñiga ${ }^{\mathrm{p}, \mathrm{q}}$, Carolina Bekker-Méndez ${ }^{\mathrm{r}}$, Julio Granados,

\footnotetext{
${ }^{a}$ Histocompatibility Laboratory, Specialty Hospital, Centro Médico Nacional de Occidente (CMNO), Instituto Mexicano del Seguro Social (IMSS), Guadalajara, Jalisco, Mexico

${ }^{\mathrm{b}}$ Department of Archaeogenetics, Max Planck Institute for the Science of Human History (MPI-SHH), Jena, Germany

${ }^{\mathrm{c}}$ Molecular Genetics Laboratory, Escuela Nacional de Antropología e Historia (ENAH), Mexico City, Mexico

${ }^{\mathrm{d}}$ Department of Biodiversity, Ecology and Evolution, Universidad Complutense de Madrid (UCM), Madrid, Spain

${ }^{\text {e }}$ Dirección de Antropología Física (DAF), Instituto Nacional de Antropología e Historia (INAH), Mexico City, Mexico

${ }^{\mathrm{f}}$ Clinical Laboratory, Unidad Médica de Alta Especialidad (UMAE) \# 2, Instituto Mexicano del Seguro Social (IMSS), Ciudad Obregón, Sonora, Mexico

${ }^{\mathrm{g}}$ Immunogenetics Unit, Técnicas Genéticas Aplicadas a la Clínica (TGAC), Mexico City, Mexico

${ }^{\mathrm{h}}$ Institute for Experimental Cellular Therapy, University Hospital Essen, Essen, Germany

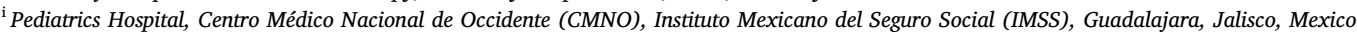

${ }^{\mathrm{j}}$ HLA Laboratory, Central Blood Bank, Unidad Médica de Alta Especialidad (UMAE) Centro Médico Nacional "Siglo XXI", Instituto Mexicano del Seguro Social (IMSS), Mexico City, Mexico

${ }^{\mathrm{k}}$ Blood Bank, UMAE Hospital de Gineco Obstetricia No. 4 "Luis Castelazo Ayala", Instituto Mexicano del Seguro Social (IMSS), Mexico City, Mexico

${ }^{1}$ Department of Nephrology and Transplantation Unit, Centro Médico Nacional de Occidente (CMNO), Instituto Mexicano del Seguro Social (IMSS), Guadalajara, Jalisco, Mexico

${ }^{\mathrm{m}}$ Central Office of Nephrology, Centro Médico Nacional de Occidente (CMNO), Instituto Mexicano del Seguro Social (IMSS), Guadalajara, Jalisco, Mexico

${ }^{\mathrm{n}}$ Central Office of Transplantation, Centro Médico Nacional de Occidente (CMNO), Instituto Mexicano del Seguro Social (IMSS), Guadalajara, Jalisco, Mexico

${ }^{\circ}$ Department of Cancer Immunology and Virology, Dana-Farber Cancer Institute, Boston, MA, USA

${ }^{\mathrm{P}}$ Laboratory of Immunobiology and Genetics, Instituto Nacional de Enfermedades Respiratorias (INER) Ismael Cosío Villegas, Mexico City, Mexico

${ }^{\mathrm{q}}$ Tecnologico de Monterrey, Escuela de Medicina y Ciencias de la Salud, Mexico City, Mexico

${ }^{\mathrm{r}}$ Immunology and Infectology Research Unit, Infectology Hospital, Centro Médico Nacional "La Raza”, Instituto Mexicano del Seguro Social (IMSS), Mexico City, Mexico

${ }^{\mathrm{s}}$ Department of Transplantation, Instituto Nacional de Ciencias Médicas y Nutrición "Salvador Zubirán" (INCMNSZ), Mexico City, Mexico
}

\section{A R T I C L E I N F O}

\section{Keywords:}

HLA

Immunogenetics

Population genetics

Baja California

Admixture

\begin{abstract}
A B S T R A C T
We studied HLA class I (HLA-A, -B) and class II (HLA-DRB1, -DQB1) alleles by PCR-SSP based typing in 250 Mexicans from the states of Baja California Norte and Baja California Sur living in Mexicali $(\mathrm{N}=100)$, La Paz $(\mathrm{N}=75)$, Tijuana $(\mathrm{N}=25)$ and rural communities $(\mathrm{N}=50)$ to obtain information regarding allelic and haplotypic frequencies. The most frequent haplotypes for the Baja California region include nine Native American and five European haplotypes. Admixture estimates revealed that the main genetic components are European (50.45 $\pm 1.84 \%$ by ML; $42.03 \%$ of European haplotypes) and Native American (43.72 $\pm 2.36 \%$ by ML;
\end{abstract}

\footnotetext{
Abbreviations: HLA, human leukocyte antigen; MPA, most-probable ancestry; LD, linkage disequilibrium

* Corresponding authors at: Department of Archaeogenetics, Max Planck Institute for the Science of Human History, Kahlaische Strasse 10, 07745 Jena, Germany

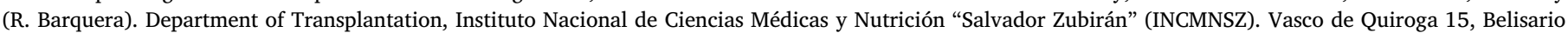
Domínguez Sección XVI, 14080 Tlalpan, CDMX, Mexico (J. Granados).

E-mail addresses: barquera@shh.mpg.de (R. Barquera), julgrate@yahoo.com (J. Granados).

URLs: http://www.shh.mpg.de/en (R. Barquera), http://www.innsz.mx (J. Granados).

${ }^{1}$ These authors contributed equally to the present work.
} 
$40.24 \%$ of Native American haplotypes), while the African genetic component was less apparent (5.83 $\pm 0.98 \%$ by ML; $9.36 \%$ of African haplotypes).

Baja California is located in the northwestern region of Mexico (Fig. 1), bordering on the northwest to the state of Sonora and on the north to the American state of California. Its condition as a peninsula, coupled with its unique demographic history, gives it a special interest when it comes to studying and genetically characterizing its population. At least 10,000 years ago, different human groups started coming to the Peninsula, according to organic settlement evidence accumulated by people who ate shellfish. Radioactive 14 carbon tests on material from Punta Minitas (7020 \pm 260 years ago) and San Quintin (6165 \pm 250 years ago) is evidence of that early presence [1]. Moreover, lithic utensils found in the middle north of the territory have sufficient affinity to be related with the prehistoric complex of Arizona's southwest or with the third phase of San Dieguito's complex, which is chronologically situated from 7000 to 5000 BC. According to this evidence, different waves of settlement have been suggested in which the oldest population entering the region would have been the first one to reach the southern tip of the peninsula. As mentioned before, there is not sufficient linguistic evidence to support these conclusions and the cultural heritage interpretations have the problem of ubiquity of adaptive constraints because of the lack of options in front of very specific pressures. It can be argued the same about the scientific studies based on craniometrical morphology [2]. Because of the differences of those that we call hyperdolicocephalic groups, there are some statements about different migrations, but the constraints of the different niches can accept an explanation of local adaptive traits. If we consider that Baja California Peninsula has an extension of $143,780 \mathrm{~km}^{2}$ with a length over $1200 \mathrm{~km}$ and a seashore of $3500 \mathrm{~km}$ with a huge desert land, and we think about the lack of big populations, the only strong conclusion is settlements with morphological and cultural stability in multiple isolations and local adaptability. This is why molecular evidence will be needed.

Even though the peninsula's current population exceeds the figure of $3,584,000$ inhabitants $[3,4]$, in the middle of 20 th century it there were less than 200,000 inhabitants and the majority came from the continental mass [5]. Historical continuity studies of that population in terms of identity have had less attention than other originating Mexican groups. Moreover, except for some native prehispanic languages that belong to the linguistic family Cochimi-Yumana that still exists in the north of Mexico, the rest of the languages actually disappeared in the 18 th century when the extinction of the majority of the aboriginal groups had started. This is why the little is known about groups like the Waycura, the Aripe and the Pericues is thanks to the missioner chronicles, the precarious archaeological evidence and the osteological and molecular studies in some human remains.

Diverse tribes, in constant struggle, occupied the territory, in communities very different to those of Mesoamerican societies and of course European ones [6]. The inhabitants of Baja California at the time of contact with Europeans had no cities, no masonry constructions, no elaborate religion; they virtually did not practice agriculture and lived on the harvesting of fruits (pitahaya was an important part of their diet), hunting and fishing. It is not possible to specify the number of inhabitants that the Peninsula had in the years immediately before the arrival of the Spaniards [6]. The Europeans arrived in Baja California in 1530 and according to their testimony, there found four native groups: Yumanos, Cochimíes, Guaycuras and Pericúes, distributed from north to south respectively. Most of these groups disappeared or were diluted by the mid-eighteenth century.

In terms of population volumes, which are the first markers of the migration phenomenon (immigration or emigration) possibly from other parts of Mexico and from the expansion of the American Southwest [7], in the case of the Baja California peninsula during the 19th century were about 4508 inhabitants for 1803 to 43,282 inhabitants for the first modern Mexican census in 1895, that is, an increase of more than $900 \%$ in 92 years. Still, part of this demographic expansion could be explained from the natural growth of the population (births minus deaths).

As of that date, there was an important migration composed of Europeans, Novohispanos and continental Native Americans. However, to this demographic reality we must add the presence of African and Asian (mainly from China and Philippines) populations, who worked respectively as stevedores in the ports or as traders in the route of the Manila Galleon that connected commercially the ports of Acapulco and Manila. Baja California is therefore an interesting mixed ancestry population resulting from the anachronistic contribution of different human groups, and recent migration from USA and Canada [8].

For the present work, we analyzed HLA class I $(H L A-A,-B)$ and class II (HLA-DRB1, -DQB1) PCR-SSP typings in 250 Mexicans from the region of Baja California [the region of Baja California (includes both Baja California Norte and Baja California Sur) data here analyzed is composed by the following populations: Mexico Baja California, Mexicali,

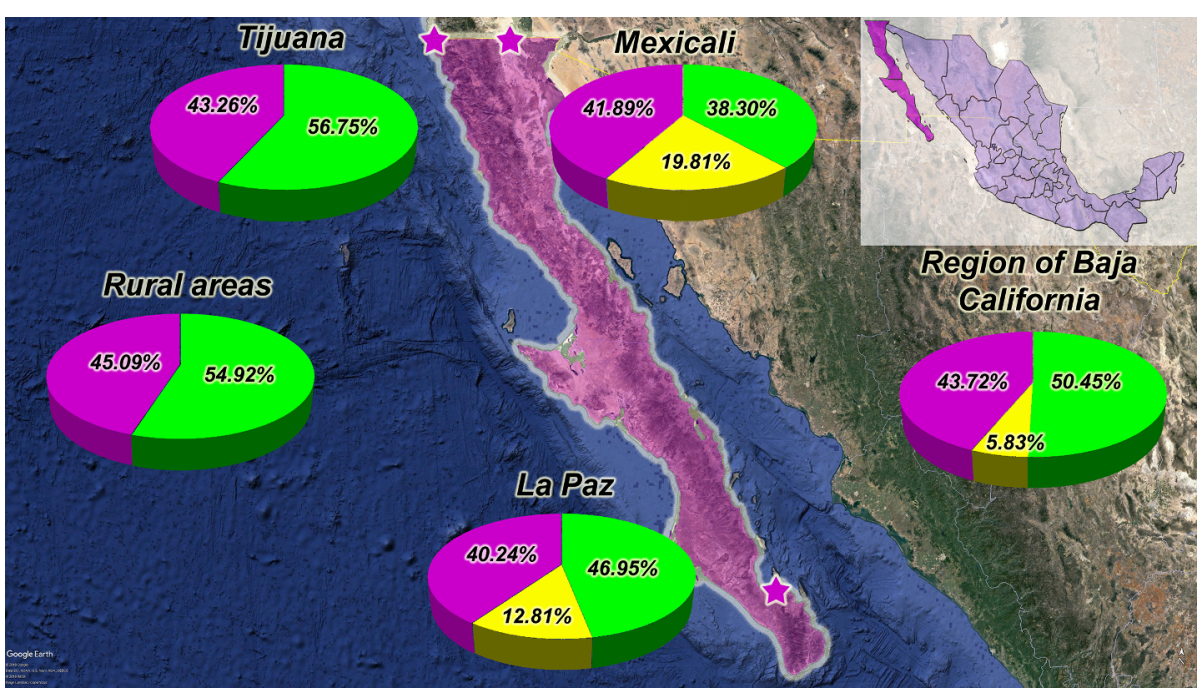

Fig. 1. Geographic situation of the region of Baja California and admixture proportions for the region of Baja California [composed by the following populations: Mexico Baja California, Mexicali, $\mathrm{N}=100$, Allele Frequencies Net Database Identifier (AFND-ID): 3527; Mexico Baja California, La Paz, $\mathrm{N}=75$, AFDN-ID: 3526; Mexico Baja California, Tijuana, $\mathrm{N}=25$, AFDN-ID: 3615; Mexico Baja California Rural, $\mathrm{N}=50$, AFND-ID: 3571]. Admixture proportions were estimated by ML using $H L A-A,-B$ and $-D R B 1$ frequencies as genetic estimators. Green refers to the proportion of European contribution, purple to Native American contribution and yellow depicts African contribution. Map modified from Google Maps Pro [15]. 
$\mathrm{N}=100$, Allele Frequencies Net Database Identifier (AFND-ID): 3527; Mexico Baja California, La Paz, N = 75, AFDN-ID: 3526; Mexico Baja California, Tijuana, $\mathrm{N}=25$, AFDN-ID: 3615; Mexico Baja California Rural, $N=50$, AFND-ID: 3571 ]. In addition to the individual populations we also show data for these combined populations. This latter data is not held on AFND to prevent duplication of data. Maximum-likelihood (ML) frequencies for alleles and four-locus haplotypes were estimated using an Expectation-Maximization algorithm. For a comprehensive review on the methods, such as sample collection, HLA typing and statistical analyses, please refer to Ref. [9] in this same issue. For the frequencies of $H L A-A,-B,-D R B 1$ and $-D Q B 1$ and haplotypic data for the sample sets of the region of Baja California please refer to the Supplementary Information: Supplementary Tables 1-9. For data on Hardy-Weinberg equilibrium (HWE) please see Supplementary Information: Supplementary Table 10 of this work and Supplementary Information: Supplementary Table 9 in Ref. [9] in this same issue. The most frequent haplotypes for the state (haplotypic frequency, H.F. $\geq 1.0 \%$, arbitrarily; Supplementary Table 5) include nine Native American MPA (HLA-A*02 B*35 DRB1*04 DQB1*03:02, $\mathrm{A} * 02 \sim \mathrm{B} * 35 \sim \mathrm{DRB} 1 * 08 \sim \mathrm{DQB} 1 * 04$,

$\mathrm{A} * 02 \sim \mathrm{B} * 39 \sim \mathrm{DRB} 1 * 04 \sim \mathrm{DQB1} * 03: 02$,

$\mathrm{A} * 68 \sim \mathrm{B} * 40: 02 \sim \mathrm{DRB1} * 04 \sim \mathrm{DQB1} * 03: 02$,

$\mathrm{A} * 02 \sim \mathrm{B} * 40: 02 \sim \mathrm{DRB} 1 * 08 \sim \mathrm{DQB} 1 * 04$,

$\mathrm{A}^{* *} 24 \sim \mathrm{B} * 39 \sim \mathrm{DRB} 1 * 04 \sim \mathrm{DQB} 1 * 03: 02$,

$\mathrm{A} * 02 \sim \mathrm{B} * 40: 02 \sim \mathrm{DRB} 1 * 04 \sim \mathrm{DQB1} * 03: 02$,

$\mathrm{A}^{*} 02 \sim \mathrm{B} * 39 \sim \mathrm{DRB1}{ }^{* *} 08 \sim \mathrm{DQB} 1 * 04$ and $\mathrm{A} * 31 \sim \mathrm{B} * 35 \sim$ DRB1*04 DQB1*03:02) and five European MPA haplotypes (HLA$\mathrm{A} * 29 \sim \mathrm{B} * 44 \sim \mathrm{DRB} 1 * 07 \sim \mathrm{DQB1} * 02$,

$\mathrm{A} * 33 \sim \mathrm{B} * 14: 02 \sim \mathrm{DRB} 1 * 01 \sim \mathrm{DQB} 1 * 05$,

$\mathrm{A} * 02 \sim \mathrm{B} * 18 \sim \mathrm{DRB} 1 * 03: 01 \sim \mathrm{DQB} 1 * 02$,

$\mathrm{A} * 03 \sim \mathrm{B} * 07 \sim \mathrm{DRB} 1 * 15 \sim \mathrm{DQB1} * 06$ and $\mathrm{A} * 11 \sim \mathrm{B} * 18 \sim$ DRB1 $* 11 \sim$ DQB1*03:01). Admixture estimates (Fig. 1) revealed that the main genetic components are European $(50.45 \pm 1.84 \%$ by the ML method and $42.03 \%$ by estimating the proportion of European haplotypes) and Native American $(43.72 \pm 2.36 \%$ the ML method and $40.24 \%$ by estimating the proportion of Native American haplotypes), while the African genetic component was less apparent $(5.83 \pm 0.98 \%$ by the ML method and $9.36 \%$ by estimating the proportion of African haplotypes). Proportions vary among the different datasets from the region. The city of La Paz shows roughly the same amount of European (46.95 $\pm 6.77 \%$ by ML and $40.00 \%$ of European haplotypes) and Native American $(40.24 \pm 5.08 \%$ by ML and $38.00 \%$ of Native American haplotypes) components, with a prominent African contribution (12.81 $\pm 9.65 \%$ by ML and $12.67 \%$ of African haplotypes). Even though Mexicali is very far away from La Paz, it exhibits very similar results: virtually equal European $(38.03 \pm 3.85 \%$ by $\mathrm{ML}$ and $44.50 \%$ of European haplotypes) and Native American (41.89 $\pm 2.99 \%$ by ML and $44.00 \%$ of Native American haplotypes) components, with an important African contribution $(19.81 \pm 5.64 \%$ by ML and $8.50 \%$ of African haplotypes). Surprisingly, Tijuana and the rural communities show a similar, and somewhat unexpected, profile: due to their classification as migration attractors [10], we expected them to bear a higher Native American and probably African components. Instead, they show a higher European component (Tijuana: $56.75 \pm 6.63 \%$ by ML and $44.00 \%$ of European haplotypes; rural areas: $54.92 \pm 2.25 \%$ by ML and $39.00 \%$ of European haplotypes) than the Native American one (Tijuana: $43.25 \pm 1.04 \%$ by ML and $42.00 \%$ of Native American haplotypes; rural areas: $45.09 \pm 6.34 \%$ by ML and $44.00 \%$ of Native American haplotypes), and a low African contribution (Tijuana: $0.00 \pm 6.30 \%$ by ML and $6.00 \%$ of African haplotypes; rural areas: $0.00 \pm 4.52 \%$ by ML and $8.00 \%$ of African haplotypes). This profile, contrasting with previous reports [11], may be explained by the important amount of foreign immigrants born in USA moving into the Mexican side of the border zone [8].

The presence of Asian haplotypes in the region (Baja California region: 5.98\%; La Paz: 8.00\%; Mexicali: 4.00\%; Tijuana: 6.00\%; rural areas: $8.00 \%$ ) can be explained by the immigration of Asians escaping from California by the end of the 19th century and the beginning of the 20th century and settling in northern Mexico before the violence held against them during the first decades of the last century in Mexico [12], but also by immigrants arriving into the region from the Philippines, China and East Asia in general, using the transpacific commercial route known as the Manila Galleon during the Colonial period [13]. The admixture estimates and the presence of Native American, European and Asian haplotypes can be explained by the aforementioned historical events that shaped the demographic traits of the present-day region of Baja California, but also exhibit some specific traits that could help shape questions arising from historical and archaeological contexts. All data from our sample sets, both frequencies and individual genotypes, can be found at The Allele Frequency Net Database website (www. allelefrequencies.netwww.allelefrequencies.net) [14].

\section{Appendix A. Supplementary data}

Supplementary data to this article can be found online at https:// doi.org/10.1016/j.humimm.2019.06.007.

\section{References}

[1] C.L. Hubbs, G.S. Bien, H.E. Suess, La Jolla natural radiocarbon measurements IV, Radiocarbon 7 (1965) 66-117, https://doi.org/10.1017/S0033822200037097.

[2] R. González-José, A. González-Martín, M. Hernández, H.M. Pucciarelli, M. Sardi, A. Rosales, S. van der Molen, Craniometric evidence for palaeoamerican survival in Baja California, Nature 425 (2003) 62-65, https://doi.org/10.1038/nature01923.1.

[3] Instituto Nacional de Estadística y Geografía (INEGI), Conociendo Baja California Sur, sixth ed., Instituto Nacional de Estadística y Geografía, Mexico, 2016, , https:// doi.org/10.5558/tfc2015-067.

[4] Instituto Nacional de Estadística y Geografía (INEGI), Conociendo Baja California, sixth ed., Instituto Nacional de Estadística y Geografía, Mexico, 2016.

[5] J. Sobrino, Migración interna en México durante el siglo XX, first ed., Consejo Nacional de Población, Mexico City, 2010http://www.conapo.gob.mx.

[6] E.L. Villicaña, Evolución demográfica de la Baja California, Historia Mexicana 9 (1959) 249-268 http://www.jstor.org/stable/25134999.

[7] M.A. Magaña Mancillas, El poblamiento de Baja California durante el siglo XIX: reflexión desde la historia demográfica, Estudios Fronterizos 5 (2004) 117-134.

[8] INEGI, Los extranjeros en México, Mexico City, 2014, https://doi.org/10.1016/ 0306-4522(87)92980-0.

[9] R. Barquera, D.I. Hernández Zaragoza, A. Bravo Acevedo, E. Arrieta Bolaños, S. Clayton, V. Acuña Alonzo, et al., The immunogenetic diversity of the HLA system in Mexico correlates with underlying population genetic structure, Hum. Immunol. (2019).

[10] Sistema de Información del Desarrollo Social, La novedad (urbana) de los antiguos, in: Gaceta Oficial Del Ciudad de México, Indígenas, Sistema de Información del Desarrollo Social (SIDESO), Mexico City, 2007http://www.sideso.cdmx.gob.mx/ index.php?id $=34$.

[11] B.Z. González-Sobrino, A.P. Pintado-Cortina, L. Sebastián-Medina, F. MoralesMandujano, A.V. Contreras, Y.E. Aguilar, et al., Genetic diversity and differentiation in urban and indigenous populations of Mexico: patterns of mitochondrial DNA and Y-chromosome lineages, Biodemogr. Social Biol. 62 (2016) 53-72, https://doi.org/ 10.1080/19485565.2015.1117938.

[12] J.J. Gómez Izquierdo, El movimiento antichino en México (1871-1934) : problemas del racismo y del nacionalismo durante la Revolución Mexicana, Instituto Nacional de Antropología e Historia, Mexico City, 1992.

[13] R. Carrillo, Asia llega a América. Migración e influencia cultural asiática en Nueva España (1565-1815), Asiadémica 3 (2014) 81-98.

[14] E.J.M. dos Santos, A. McCabe, F.F. Gonzalez-Galarza, A.R. Jones, D. Middleton, Allele frequencies net database: improvements for storage of individual genotypes and analysis of existing data, Hum. Immunol. 77 (2016) 238-248, https://doi.org/ 10.1016/j.humimm.2015.11.013.

[15] Google, Google Earth Pro(C, 2019. earth.google.com. 